\title{
Reflections on Resilience. A Teacher's Professional Learning Journey
}

\author{
Marianna Fokaidou, ${ }^{1, *} \&$ Pavlina Hadjitheodoulou Loizidou ${ }^{2}$ \\ ${ }^{1}$ Primary Education, Ministry of Education and Culture, Nicosia, Cyprus \\ ${ }^{2}$ Cyprus Pedagogical Institute, Ministry of Education and Culture, Nicosia, Cyprus \\ *Correspondence: Primary Education, Ministry of Education and Culture, Nicosia, Cyprus. E-mail: \\ mfokaidou@cytanet.com.cy
}

Received: February 4, 2019

Accepted: March 21, 2019 Online Published: August 25, 2019

doi:10.5430/jct.v8n3p171

URL: https://doi.org/10.5430/jct.v8n3p171

\begin{abstract}
The purpose of this study is to describe and reflect on the route a teacher followed to implement an inquiry-based professional learning cycle in her everyday practice and form a conceptual framework for teacher professional learning on resilience. The teacher acted as a researcher and worked with a facilitator to explore the experience of three twelve-year-old migrant students with high learning performance in an urban school in Cyprus. Diverse aspects considered as important determinants for their educational success and resiliency were explored through case study research. The data were analysed and three main categories related to resilience were formed: emotional resistance, development of responsibility and sense of belonging. The main findings of the exploratory study were used as the cornerstone for school-based teacher professional learning focusing on methods, approaches and aspects that could be applied in order to strengthen all students and enhance positive impact on students' achievement.
\end{abstract}

Keywords: resilience, migrant students, academic performance, identity, teacher professional learning

\section{Introduction}

Among factors which can influence school success of migrant students, implementation of the education policy is regarded as the most decisive (Heckmann, 2008). Educational systems play an important role in integrating migrant students as they are expected to anticipate the challenges inherent in diverse student populations (NESSE 2008; OECD, 2015; SIRIUS, 2014). Educational systems are expected to secure educational achievement by designing and implementing educational programs and activities in schooling that promote equality for opportunities for all, fight discrimination, and enable students to take full advantage of their potential (Gotovos, 2002; NESSE, 2008). General characteristics of the education system, teacher expectations, classroom environments and school organization seem to contribute to shaping migrant students' learning experience through interaction with individual characteristics of students (NESSE, 2008; Nusche, 2009). In particular, it has been noted that programs which address the cognitive and psycho-social needs of students offered early on, can eliminate exclusion (social and educational) that is caused by gaps in knowledge and difficulties in communication (NESSE, 2008; OECD, 2015; SIRIUS, 2014). Migrant students are often found to have lower education outcomes than their native peers and show, significant performance gaps compared to native students due to language difficulties, low socioeconomic context and cultural orientation of the family(note 1). (Nusche, 2009; OECD, 2011; OECD, 2012). Focus on resilient students, the students who are in the most disadvantaged quartile of students in their country, but, nevertheless, score in the top quarter of assessments, suggests that top-performing educational systems succeeded in supporting the disadvantaged at-risk students to achieve high academic performance (OECD, 2012).

Studies on resilience have traditionally described internal and external protective factors that counteract negative effects of trauma and/or adversity, through a process similar to building immunity from disease, which contributes to rebounding from exposure to risk and to becoming stronger against future stressors (Anthony and Cohler, 1987; CARRI, 2013; Masten, 2000). Criticism of this framework showed that the focus on invulnerability overemphasized innate traits and personal strengths like social skills, problem-solving ability, and self-regulation as contributors to resilient outcomes (Cloitre, Martin, and Linares, 2005). Under this perspective there were references to "social strengths" like the capacity of the migrant families to adapt their belief systems and make meaning of adversity. 
Challenges of migrant life were perceived as opportunities to improve quality of life and to secure children's future (Walsh, 2003, Parra-Cardona et al., 2006). Butler (1997) referred thus to resilience as an interactive and systematic relationship between inner strengths and outer help throughout life. Care and support, opportunities for meaningful and active participation, vision for the future, social competences, and problem solving skills were mentioned as factors which enable students to get over adversity (Benard, 1991; Benard, 2004; Garmezy and Rutter, 1983).

In particular, a study by Kossek and Burke (2014) emphasized how crucial the impact on teenage students is when having someone in their lives who believed in and cared about them as individuals, regardless of their choices. Parents, grandparents and siblings were found to encourage students to persist and their teachers were described as willing to help, and believing in success. When there was a lack of support from home, teacher relationships were of crucial importance in empowering students to overcome their circumstances. At the same time immigrant groups were found to be particularly good at organizing and utilizing resources because of having as parents higher expectations for their children (i.e. getting better jobs) (SIRIUS, 2014).

Experiences which draw students out of failure and towards success seem to formulate three different categories: a. participation in school assignments or programs which are meaningful and related to future plans, $b$. athletics and $\mathrm{c}$. outside experiences such as raising a child, being involved in church, or holding jobs that provide connection and meaning (Kossek and Burke, 2014). Modood (1993, 2004) used the concept of "mentality", referring to "the 'motor'...overcoming disadvantage (which) lies in migrant parents getting their children to internalize high educational ambitions and to enforce appropriate behaviour" (Modood, 2004, p. 87).

It is therefore of crucial importance for teachers to see how the diverse student characteristics are associated with resilience and identify any interconnection in the relationships of resilience to student approaches to learning, as well as interrelations of socio-economic disadvantage with academic achievement or with other issues such as gender, language or migrant background (OECD, 2011; OECD, 2012). At the same time resilience analysis can enable how risks can be identified and addressed and how power dynamics are evolved in order to strengthen the resilience of migrant students through policies and strategies (OECD, 2016).

\subsection{The Cyprus Educational Context}

\subsubsection{The Structure of the Educational System}

The Educational system in Cyprus is a highly centralized system in which the Ministry, made up of hierarchies and different departments, is responsible for the management of education, the enforcement of educational laws, the preparation of educational bills as public education is financed by the Government, the prescription of syllabi, curricula and textbooks, the regulation and supervision of educational institutions, the construction and maintenance of school buildings and equipment as shared responsibility with local School Boards. Different departments at the Ministry of Education and Culture are responsible for the different educational stages: The Department of Primary Education is responsible for Pre-Primary Education which is compulsory for all children between 4 8/12 - 5 8/12 years old and Primary education which is compulsory for all children over the age of $58 / 12$ and has a duration of 6 years.

The Cyprus Pedagogical Institute is one of the Departments of the Ministry of Education and Culture, established by a Council of Ministers decision in 1972. It is responsible for the teachers' continuous professional development and learning with an emphasis on school-based schemes taking into account international and European trends in education, local needs and priorities. It also has the role of advising and facilitating the Ministry educational policy development.

The current context of the Cyprus educational system is shaped by a process of reforms starting back in 2004. A series of measures focusing on the restructuring of the Ministry's Strategic planning, the teachers' appointment system, their continuous professional development and learning, as well as their evaluation and the upgrading of the content of education (new revised curricula, language teaching, restructuring of upper secondary education), upgrading secondary technical and vocational education, promotion of open and distance learning in order to improve school effectiveness, have been taken since.

\subsubsection{The Teacher Professional Learning Policy}

According to the World Bank report "Teacher Policies in the Republic of Cyprus" (2014) as an outcome of advisory actions following the economic crisis in Cyprus, changes in teacher professional learning, were necessary since teacher professional learning structures had not been supportive and systematic and policy recommendations were made on teachers' learning to ensure that mandatory teacher professional learning would be linked to teachers' needs. As a consequence a Scientific Committee was estyablished and the report of the Committee "Towards a Uniform Policy for Teachers' Professional Learning" (March, 2015) presented the theoretical framework underpinning the 
proposed reform in teachers' learning, described the existing situation and recommended expansion of teacher professional learning opportunities at the level of the school as well as association of this to whole-school evaluation. A number of recommendations made in the Report of the Scientific Committee, with an emphasis on a school-centered form of teachers' learning, were taken up through a ministerial decision in summer 2015. According to the new teacher professional learning model in each participating school, a facilitator would work in cooperation with the head teacher, the school coordinator and the teachers, in order to support the process towards promoting teachers' professional learning in the school context. By investigating the conditions within which they work (Altrichter, Posch, and Somekh, 2001), teachers would identify needs and form training in the context of everyday work (Yin, 1994) and elaborate useful conclusions. This initiative sought actually to introduce the interaction of teachers through a learning cycle, which would work to diagnose teacher learning needs in the school context and then plan, implement, and evaluate a more personalised programme at the whole-school level. One of the principal aims stated was the improvement of the quality of the teachers' practice by being engaged in research, critical reflection and professional sharing of day to day practice. The teacher professional learning methodology through such a supporting program implemented by the Cyprus Pedagogical Institute focused on fostering a systematic process of reflection, investigation, planning and evaluation of training activities for the benefit of students, and the professional learning of teachers (Avgitidou, 2015). Critical awareness of educational process through investigating the school context and reflecting on action was the main aim. Teachers had to choose one everyday pedagogical issue to focus on, explore different perspectives of all significant others in the school role set, plan actions, implement and evaluate prioritized educational strategies and actions. Through critical reflection teachers would work as researchers of their own pedagogical decisions and practices (Cyprus Ministry of Education and Culture, 2015). Teachers, as active learners who thus face dilemmas in their practice and professional learning, would be able to know, enrich, rethink, observe and improve their practice. The model was suggested for connecting pedagogy with educational practice (Avgitidou, 2014, 2015) through focusing on the educational context, recognizing the consequences of teachers' decisions and actions and redesigning in order to improve teacher work. The children's performance was the basis for reflective investigations and knowledge building for teachers themselves (Avgitidou, 2014).

The cycle for teacher professional learning consisted of four steps based on the model implemented by the Cyprus Pedagogical Institute (Avgitidou, 2015), as shown in the diagram below:

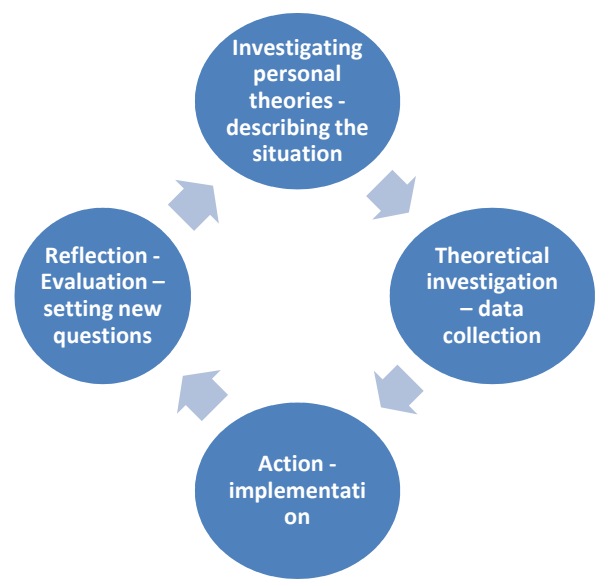

Diagram 1. The Teacher Professional Learning Cycle Through Action Research (based on Avgitidou, 2015)

Teacher professional learning is a complex activity that is multi-causal, multi-dimensional and multi-quarrelational (Opfer and Pedder, 2011). It relates to teachers as individuals (e.g. their prior experience and knowledge, their orientation and beliefs, their enactment in classroom) practice, the school (e.g. sociocultural context, the collective orientations, beliefs about learning and practices of the staff, the norms) and the learning activities per se. Since teachers need time to develop, discuss and practice, their professional learning activities need to be systematic, sustained and intensive (Garet et al., 2001). Teachers learn effectively when learning activities are school - based, integrated into daily work and require collective participation (Opfer and Pedder, 2011). Collective, reflective school-based and practice- based professional learning leads to change (e.g. Cheng, 2017) and empowers new skills development and the use of lenses through which needs can be identified and covered (Luckin et al., 2017).

Reflection and enactment are actually the main means through which change in a system of teacher's world can take 
place and proves the cyclic nature of teacher change (Clarke and Hollingsworth, 2002). Opportunities for field and classroom experiences, reflection, understanding oneself in a secure environment under challenging circumstances, applied knowledge (Opfer and Pedder, 2011), collaborating with peers and working with experts on topics relevant to the teachers' practice, promote reflective practice and provide a supportive context for teachers (Camburn and Won Han, 2017).

Through the new policy on teacher learning it is expected that critical reflection will enable teachers to work as researchers of their own pedagogical decisions and practices through "critical thinking and probing, challenging assumptions and practices, renewing decisions and activities... (being) positive to change, tak(ing) into account new ideas in relation to teaching and learning." (Ministry of Education and Culture, 2015, p.3).

\subsubsection{Policy on Integration of Students with Migrant Background}

In the last few decades Cyprus has increasingly become a receiving country of immigrants, making it very different from the seemingly culturally homogeneous place it once considered itself to be. All children in Cyprus have the right to enroll in public educational institutions, irrespective of their residence status or nationality. In Cyprus, children with 'a migrant background' are children who are immigrants themselves or have immigrant parents. According to data available by the Department of Primary Education (Ministry of Education and Culture) (http://www.moec.gov.cy/dde/en/index.html), approximately 14\% of the school population in Cyprus do not speak Greek (the official public-school language) as their first language with the top four countries of origin being Romania, Georgia, Bulgaria and Syria.

The teachers' role and their learning in promoting students' learning and achievements is closely related to issues of migrant students' success as stated in the Policy Paper on the Integration of students with migrant background in the Cyprus educational system" (Ministry of Education and Culture, 2016). Reception of newly arrived students, smooth transition from reception to integration, teaching and evaluating Greek as a second language, mapping out migrant populations in schools, integrating intercultural perspectives and antiracism in schools, teacher professional learning on issues related to migration, are the main pillars of the 2016 MOEC's policy paper and action plan for integrating students with a migrant background into schools (http://www.pi.ac.cy/pi/files/epimorfosi/entaxi/policy_paper.pdf). The policy focuses on revision of relevant definitions and terms (children with a migrant background, second language), mapping of migrant population, combatting racism, implementation of preparatory, transition and induction-support phases and of a system combining intensive teaching and language learning support (teaching methodology and materials, teacher manuals, afternoon classes, Content and Language Integrated Learning approach, mentors etc.), utilising and teaching mother tongue languages, training of teachers and school leaders (holistic and intercultural approach), cooperation of schools with local authorities and the community (educating and involving parents, welcoming newly arrived students, involvement of parents or members of the migrant groups as mediators or mentors).

Policy implementation measures include online information for schools on reception of newcomers (guide for the first days at school, tests for knowledge diagnosis, etc. as well as a guide for parents acting as mediators for newly arrived families), teaching Greek as a second language (different schemes in primary and secondary education based on a pull-out system so that children spend some time in the general class and some in the second language class). Procedures for diagnosis/mapping of competences through standardised diagnostic tests to identify level of Greek language based on the Common European Framework of Languages are also implemented. Teaching material and guides for teaching Greek as a second language as well as of communicating with parents have been developed. Data collection/monitoring is achieved through an online platform for primary schools and different teacher training schemes are offered (afternoon seminars, conferences, distance learning seminars, etc.) while all material from different trainings and guides is available online. Finally, an intercultural dimension in Curricula and a code of conduct on antiracist behaviour at schools are promoted.

\section{Methodology}

The purpose of the study was to explore the route a teacher followed to implement an inquiry based professional learning procedure in her everyday practice at school in order to investigate resilient migrant students. The questions addressed in the study were:

- Which experiences of migrant students could be related to motivation or lead to positive results?

- In what ways can this process represent a conceptual framework for teacher professional learning on resilience? 


\subsection{Research Design}

For the purpose of the research the exploratory case study methodology was implemented. According to Tellis (1997), the case study research enables the researcher to go beyond the quantitative statistical results and understand conditions through the actor's perspective in closely examining the data within a specific context. In most cases, a small geographical area or a very limited number of individuals are selected and contemporary real-life phenomena are investigated through detailed contextual analysis of events and their relationships. It "involves the study of an issue explored through one or more cases within a bounded system, a context" (Creswell, 2007, p. 73) which for the present study is the teacher's experience of a professional learning which focused on three resilient students. The teacher aimed at providing a "rich, thick description" (Glesne, 2016 p. 53) of a phenomenon in detail from her point of view. This demanded a detailed, in-depth data collection involving multiple sources of information (Creswell 2007, Marshall \& Rossman, 2011). Humans assign meanings to actions by focusing on thoughts, feelings, beliefs, values, and assumptions involved, and the case study researcher "needs to understand the deeper perspectives that can be captured through face-to-face interaction and observation in the natural setting" (Mashall \& Rossman, 2011, p. 91). The natural setting in this case was an urban primary school in Nicosia, Cyprus with a high percentage of students with migrant background and in particular the life stories of three students. The teacher obtained information gathered by observing the students in classroom and school yard, talking face-to-face with other teachers, parents/relatives and the students themselves. She collected multiple forms of data from observations, interviews, as well as documents, reviewed all of the data collected, and analysed it into categories. The case study utilized the framework for teacher professional learning which consisted of four steps and was implemented by the Cyprus Pedagogical Institute (Avgitidou, 2015) as the new policy for teacher professional learning, mentioned in the previous section.

Furthermore, the procedure was enriched with the cooperation of the teacher-researcher with a facilitator-critical friend, who enabled reflection in the implementation of the model as proposed by the Cyprus Pedagogical Institute to explore the case of the three resilient students' biographies and school performance and the teacher's and her colleagues' work with migrant students. The critical friend is, according to Costa \& Kallick (1993), a trusted person who asks provocative questions, provides data to be examined through another lens, offers critique of a person's work as a friend and fully understands the context to advocate for the success of the work. The notion of a critical friend has been used extensively in the role of a professional learning facilitator in school review and improvement processes (Swaffield \& MacBeath, 2005). In this framework it was adopted in the Cyprus Pedagogical Institute model for teacher professional learning. The notion of a critical friend has been used extensively in the role of a professional learning facilitator in school review and improvement processes (Swaffield \& MacBeath, 2005).

\subsection{Setting and Selection of Participants}

The setting for the present study consisted of a public primary school in an urban area in Nicosia Cyprus. Students enrolled were aged 6 to 12 years and were distributed in six classes. The population of the school was diverse, both culturally and linguistically. The majority of students $(60 \%)$, had a migrant background coming from different countries, such as Bulgaria, Romania, Russia, Armenia and Egypt and their first language was not Greek. Most of the students came from families of low socioeconomic status. Parental support in the educational field was reported to be limited mainly due to shift working hours. Diverse attitudes towards education and language difficulties regarding the academic knowledge of the school language, and the set of other needs as priorities were also reported.

According to Creswell (2014), qualitative research focuses on participants and locations that will help the researcher understand the problem addressed. For this case study, three girls among other students of the teacher's class were selected because their school profile was in contrast with their environment. This contradiction became a source of motivation for further investigation. It generated the question of how high performance and low socioeconomic background are related in the girls' biography. Despite hard life circumstances, positive aspects seemed to influence their learning and personal development. Based on these observations, the teacher decided to investigate aspects that strengthen and enhance resiliency. The intention was to thoroughly understand these students' lives and connect them to school characteristics in order to enable working with other teachers, and implement educational routes which foster resilience among a greater number of students. Although life circumstances and definitions of situation are unique, investigating them can lead to useful conclusions for others. So in this sense the teacher aimed at empirically investigating the situation of the three girls in the real context (Yin, 1994) in order to improve teaching and learning in her school (Altrichter et al., 2001). 


\section{Findings}

The teacher in cooperation with the facilitator employed mixed methods to collect data from the micro-level of classroom and the meso-level of school. The data collection was a combination of observations, discussions, and document analysis, relevant to the study.

These were analysed to form categories referred to as commonalities through thematic analysis, in order to identify important items about the data that related to the research questions which represented a pattern in response or meaning within the data set (Braun \& Clark, 2006, p. 82). The aim was to "arrive at a more nuanced understanding of some social phenomenon through understanding the processes that tend to involve that phenomenon as well as the perceptions, values, and beliefs of people toward it" (Glesne, 2016, p. 184). This resulted in an in-depth descriptive analysis that addressed the research questions and identified the commonalities and patterns at the different steps of the professional learning experience. The teacher professional learning cycle on resilience was separated in four distinctive steps:

\subsection{Investigating Personal Theories on Resilient Migrant Students}

As mentioned in the teacher's journal, the life conditions of the three girls were at first glance perceived as obstacles to their school career:

Therefore, during the first month of the school year, the sixth-grade teacher - researcher focused on the girls with migrant background from Russia, Armenia and Bulgaria, born in Cyprus or migrated to the country in their very early years. They all attended school in Cyprus from the first grade. They had a very good performance throughout the six years in the primary school reflected in their assessment portfolios. The teacher was interested in finding out more about the background and personality of these girls in order to interpret their motivation. Above all, the question was raised of how, despite migration, low socioeconomic background and family problems, these three girls, had constantly high scores in all subjects and were characterized as happy, social, and dynamic. She wanted to go against prejudice and reflect on her expectations for students with migrant background in order to enhance her role in their learning. A reflection on the possibilities of positive impact that the school system, and classroom can have in order to support the learning outcomes of disadvantaged pupils was the final destination of the procedure.

Journal notes on the three children's academic performance portfolio, as well as the teacher's journal notes on interactions and incidents of daily life in school and at home, skills, attitudes and behaviors offered useful information about the socioeconomic and academic status of the parents, their attitudes and expectations related to the academic progress of their children, the house circumstances, routines and free time, important places and people influencing their lives. Using journals enabled interpretation, reflection and decision-making processes as well as the formation of a valuable context for self-knowledge and understanding of the other through critical investigation (Avgitidou, 2012, Ronnerman, 2003). The diary/journal was private and only used by the teacher for daily writings on observations, interviews and reflections. Notes were reflected upon while discussing them once a week with the facilitator to decide what to focus on during the following step/week. Reflections were either practical or theoretical and were used during and after the reflective discussions with the facilitator working constantly on the interaction of inner strengths and outer help as described by Butler (1997). The main points of interest were transformed into the two research questions mentioned in the previous section.

\subsection{Exploration of Core Concepts, Biographies and Resiliency Through Curriculum Activities}

The teacher and the facilitator started a deeper exploration of the resilience factors as described in literature, through classroom activities which would further deeply reveal the girls' voice and experiences. Both researchers proceeded to an analysis of experiences during Health Education sessions(Note 2). The activities enabled conclusions related to the impact of various factors enhancing student performance.

The lessons were planned aiming to explore the concept of identity by describing their personal life journey, and produce self-referring material, visual and textual outcomes which emerge as therapeutic 'subject-reflexive feeling' (O'Neill et al., 2002, O'Neill, 2008, O' Neil and Hubbard, 2010). Journal notes were also kept by the facilitator who was always present during and after the implementation of particular activities in the classroom. After every lesson/session the teacher and the facilitator discussed and reflected on what and why was noted and observed.

\section{Activity 1: Discussion about a personal story}

The children watched a short film which presented the first day at school of a migrant boy in the reception country. Discussion was extended to more general concepts such as the self and other and orientation and multiple facets of the migrant identity. 
All students pointed out the concept of diversity. They stressed the need and importance of friendship and collaboration they had experienced as well as the joy of giving and creating. Questions enabled reflection by comparing and contrasting events in the film and in the three girls' life biography. Through the discussions the aspect of responsibility in forming the resilient migrant identity also emerged.

The fact that I met some kind and supporting girls in the beginning of my life here, made me feel safe... (Ane)

It was not easy to see so many new faces, but now everything is nice here because everybody accepts me now. (Lydia)

\section{Activity 2: Sense of Belonging Project}

This activity was based on an idea inspired by Alex Rotas (Rotas, 2004) in the "Sense of Belonging Project". The original project was implemented with the participation of asylum seekers and refugees "claiming a creative space, a voice, and a personal and political space, in a social context where they are principally represented by others as unwelcome and threatening strangers" (Rotas, 2004, p.52). The children were asked to draw and mark on a map of the neighborhood their home, a place near their home that they consider as special, some other places which are also near and the path. Then they walked these paths with the teacher and their classmates, stopped took pictures and talked about these important places together.

According to Rotas (2004), experiencing this walk allowed children with migrant background to relate to processes of becoming, and to appreciate what it is like to make home in a place that was not home for their family from the very beginning. The process of mapping while walking led to making art to express experiences of migration and belonging in visual form (Rotas, 2004; Wylie, 2005). The activity evokes a 'potential space' (Winnicott, 1982), between ethnography and arts practice as the children explored and represented processes involved in walking that related to issues of belonging, identity, and "place-making". After the walk, children were asked to present their personal digital story of life covering areas of the self:

Activity 3: Walking and Story telling

Activity 3 was a continuation of Activity 2 as the children were asked to present their personal digital story of life covering the following areas:

Who I am...

My home - My neighborhood -My school-My favorite places

My life now - my future (15 years from now)

Children had the chance to explore different meanings related to their identity. They selected different items like pictures, photos, words, music that represent themselves and while commenting on this material, they recalled and reflected on their lives. This data was used to end up with their visual and digital own-story-telling on these topics based on a framework suggested by Blunt and Dowling (2006). During the presentation, the facilitator guided an informal interview with each student. The three girls especially had the chance to explain aspects of their personalities and their lives, which was used as data.

The three girls reflected on diverse influencing aspects and showed that young immigrants are actively engaged in producing their own hybrid, multicultural, migrant identities and sense of belonging (Anthias, 2002; Back, 1996; Cohen, 1997; Hall, 1992; Mahtani, 2001; Rattansi, 2005). The girls can act both as culturally formed and forming subjects (Lee and Pacini-Ketchabaw, 2011) and that their identities are 'flexible' and 'negotiated' but at the same time certain aspects are being imposed (Ong, 1999) while certain structures and places strengthen the sense of belonging and hope for the future.

All data were analysed and they formed three main categories. The construction and interrelation of the categories shown in the table below supports literature findings that resilience does not refer to "inborn strengths, fierce independence and rugged individualism alone" (Butler, 1997, p. 20) but it is the product of relationships of inner strengths and outer help. The three categories - skills create an "inner locus of control" an optimistic perspective of life and the confidence in the ability to shape events through competence and hope. As Werner (1995) suggested, nature and nurture constantly interact to present new choices and trajectories. 
Table 1. Resilience Skills, Connected to the Participants

\begin{tabular}{lll}
\hline Emotional management & Sense of Responsibility & Sense of Belonging \\
\hline Positive attitude & Persistence & Sharing experiences \\
Social intelligence & Creativity, love of learning & Significant Places \\
Self-regulation & Leadership skills & Significant others \\
Gratitude & & \\
\hline
\end{tabular}

\subsection{Emotional Management}

The three girls had the ability to deal with challenges and adapt to new or difficult circumstances in a productive manner.

Some evenings there was no food at home, but I knew I would run at school every morning to get my breakfast (Lydia)

They were able to evaluate situations, reflect on themselves and retry. Despite limitations, they were optimistic and respectful for daily unimportant things and led to success.

Whatever your dreams are you need to try hard... (Jeanny)

What makes me strong is when I think of others that have nothing of the things, I have... (Lydia)

Positive relationships with family members, friends and other "significant others", were crucial. These were people that they could trust, who believed in these children and could encourage them. These could either be a relative or a teacher.

I will study medicine and be a doctor... A surgeon.. I am sure about this! ... I am happy when my teachers are satisfied. They tell me very often that I will succeed ... My teachers are very important for me because they believe in me and they encourage me to try new things. They make me know that I will always succeed when I try... (Lydia)

The presence of an adult who strengthens these children was also revealed either through their help towards younger siblings.

My older cousin is very special for me. She goes to high school and I want to be like her when I grow up. She helps me with my homework and I feel safe with her...I try to teach my younger sister to read and write so that she will not have difficulties when she starts school (Jeanny).

\subsection{Sense of Responsibility}

The capability of self-exploration and reorientation, problem solving even for daily life aspects empowered them to become decision makers with strong self- esteem.

The class activity of taking pictures, made me feel very special. As I had the chance to present a part of myself and life and all the things that matter for me (Ane).

Besides dealing with adults' issues like housework or help and care towards younger siblings or taking responsibility, functioned in a constructive way. The girls being the oldest of the siblings in the family, had many responsibilities and acted in a very flexible way in all areas of their life.

When I finish school, I take care of my younger sister. I teach her things, I also help at home with washing up, cleaning and ironing. Then I do my homework. I also love reading books so I meet my friends at the library. I see my parents only at noon (Ane).

The most difficult time is the night when my mother goes to work. I take care of many things and sometimes I am afraid of the dark. I iron, wash and wait for my mother to come home. Sometimes I get tired and a bit anxious when it gets dark... (Jeanny)

They were creative and found smart solutions for every problem that appeared.

When I feel good, I have the mood and energy to do many things (Ane).

Their parents often counted on them as important members of the family and in their case, this functioned positively on their school life.

When my parents come from work, I prepare the dinner for the whole family. This is our family routine. (Ane) 


\subsection{Sense of Belonging}

Emotional bonding with significant places expressed the feeling of belonging to a member of a special group. Sharing experiences and common interests influenced the way they act and see their lives.

It is so inspiring to have friends who accept you the way you are, because you feel so real. I need them in my life (Ane).

The church, the library, the school and the neighbourhood are strongly bonded with their identity and life and influence their personal growth.

I look forward to the time when I meet with my friends for the Zumba classes in the neighborhood. We dance, have fun and prepare for the performance day. Although it is tiring, it is so relaxing after school (Lydia)

The church is a nice place, it makes me calm and I like sharing this experience with my family... We also have our breakfast, play games and learn many things about life (Ane)

The community library is my favorite place in the neighborhood... I feel nice there. It is a place where I meet friends, I can explore the place and all the books I like, people like me there, I feel that I am a part of it and it is a part of me (Jeanny).

\section{Discussion}

As the exploration of the students' cases came to an end, the project was presented to the teachers of the school, giving the opportunity for a summative evaluation and an open discussion. Sharing information and reflection concerning their role in empowering certain students was the final goal. The results were used as the starting point for the teachers' learning and action. The study provided insight into the educational and social issues confronted by these students and the factors that contributed to their resiliency. A better knowing and understanding leading to a positive teacher - student relationship emerged. The new focus was to explore the way that effective aspects function positively on participants and can be promoted in the school context in order to empower more students by gaining the sense of belonging. There was a great need for the school to create opportunities and places where the students feel that they are members and can interact with people who can influence them positively.

The study described the journey the teacher undertook in a professional learning experience on students' resilience. It contributed on learning how the teacher can explore the interaction of the students' lives with school and provided information about how actual experiences in classroom get into the framework of professional learning, answering thus, the research questions addressed in the study.

The activities designed and implemented, engaged the teacher in reflecting on the issues she was concerned about and through her practice she became both producer and consumer of knowledge. Questioning, and exploring, turned into the starting point for discussion opportunities to understand and develop practices of a particular subject in the curriculum which could reveal information on students' resilience. Special emphasis was given to the way these data could be used so that the whole school could explore and "adjust" teaching to certain identity aspects of children which are decisive in their personal and learning development. The daily experiences of each child, despite how hard and complicated they are, offered a field for further investigation and interpretation. In this way, constructive connection of how limitations and competences could be associated, gave the chance to deal with the negative circumstances of life in a positive and productive manner.

The resilience exploration during the teacher's professional learning could act as an example of how a supportive school encourages success. The study of the three girls revealed resilience as "an attribute with adaptability" at its core. Although education can be hindered due to family economic pressures, demands of the migrant life and poverty (CARRI, 2013) a "defense mechanism, enabled the three girls to thrive in the face of adversity through an interaction of management of their emotions, sense of belonging and the development of responsibilities. The activities implemented by the teacher during the Health Education lesson revealed the paths they followed as they adapt and prosper over time. According to Walsh (2003) the teacher actually had the opportunity to focus on the girls' ability to "withstand and rebound from disruptive life challenges." It was also interesting to see the capacity of the migrant families to adapt their belief systems in order to make meaning of adversity, through their high level of perceived life satisfaction despite the challenges of migrant life, and the association of these challenges with the expectations to improve their quality of life in the future.

New knowledge is expected to have a greater impact when it is shared in communities of practice or enquiry through which participants are encouraged to view research as a process through which they ask critical questions regarding 
their practices. It was decided that the particular teacher professional learning activity could be the starting point to investigate further the issue of resiliency in the school context and to plan activities. Emotional resistance, the development of responsibility and the sense of belonging were discussed as a reflection focus and the starting point for improvement. The school staff took into consideration the circumstances and environment of trust where the children would be able to create strong relationships, and promote student learning and achievement. This could for example lead to mentoring by older students - taking the responsibility of younger children, participating in actions which promote voluntarism in a systematic way or are student-centered focusing on social justice, creating corners of significant places and functions in the school schedule and classroom work or creating music, reading or drawing extra curriculum activities (Lewis-Charp and Law, 2014; NASP, 2005). Thus, the students could build up a particular set of skills to help them cope with the challenges of everyday life, and consequently develop a sense of bravery, an ability to solve problems, to stand up for their own views and beliefs, foster interests and make themselves feel better. The competencies and social capital that students acquired in school and at home were found to be major contributing factors to their resilience and academic achievement. The school could thus be oriented towards actions that encourage all students to gain skills for better results. Setting personal educational goals systematically, teaching children how to determine themselves and develop different strategies, could be the main school aims for the following school year. Furthermore, the Health Education lesson activities applied revealed how, when and why greater attention should be paid to migrant students and their families, and policies and practices that promote resilience, build on strengths and shift away from individual deficit toward positive views.

Exploiting critical awareness in the design, implementation, and evaluation of specific actions to improve or resolve issues that concern the teacher in the school community was based on the teacher's active role in shaping the content and direction of her own professional learning embedded in everyday practice. Supporting teacher professional learning aims at improving work and teacher's reaction to contemporary social and educational needs was not an input of new knowledge that has to be implemented but it derived from reflection and research in action (Altrichter et al., 2001; Avgitidou, 2014) through the study of the three girls as an inquiry-based professional learning which set new questions on how teachers can collaborate to provide support and interventions for students, focus on metacognitive reflection and continuous improvement that promotes ongoing dialogue about what is effective or not for their students. The school staff was thus found to discuss centered practice as a school reform approach driven by student learning and a commitment to equity. They discussed how their teaching practices can be flexible and responsive to students' needs and how positive and supportive relationships between students and adults in schools can enable students to succeed in school and life situations.

The teacher professional learning experience initiated a discussion and a new teachers' perspective on what Park, Peterson \& Seligman (2006), describe as moral goals that guide their members to be caring, responsible and productive people in society, when schools put in place practices that systematically build character and well-being. The journey the teacher took in exploring resilience through a case study as described above could be a good example of this perspective. Additional research could thus be conducted in the area of the migrant children's social, emotional, and intellectual school support in sources of resilience for migrants and in particular social networks for individuals and families. Further research could follow migrant students and their families longitudinally in order to better understand long-term implications of school impact on resilience and success.

\section{References}

Altrichter, H., Posch, P., \& Somekh, B. (2001). Teachers investigate their work: An introduction to the methods of action research. (translated in Greek). Athens: Metaichmio.

Anthias, F. (2002). Where do I belong? Narrating collective identity and translocational positionality. Ethnicities, 2, 491-514. https://doi.org/10.1177/14687968020020040301

Anthony, E. J., \& Cohler, B. (Eds.). (1987). The invulnerable child. New York: Guilford Press.

Avgitidou S. (2012). The use of journals in educational action research: presuppositions and processes. Retrieved 8/6/2015 from http://www.actionresearch.gr/AR/ActionResearch_Vol2/ Issue02_04_p29-48.pdf

Avgitidou, S. (2014). The teachers as researchers and reflective practitioners: supporting professional learning for a participatory and collaborative education (in Greek). Athens: Gutenberg.

Avgitidou, S. (2015). Teacher Professional Learning through Action Research. A Guide to Support Teachers and Schools in Everyday Pedagogy (in Greek). Nicosia: Cyprus Pedagogical Institute. 
Back, L. (1996). New ethnicities and urban culture. New York: St. Martin's Press.

Benard, B. (1991). Fostering resiliency in kids: Protective factors in the family, school, and community. Portland, OR: Western Regional Center for Drug-Free Schools and Communities, Northwest Educational Laboratory.

Benard, B. (2004). Resiliency: What we have learned. San Francisco, GA: West Ed.

Blunt, A., \& Dowling R. (2006). Home. London: Routledge. https://doi.org/10.4324/9780203401354

Braun, V., \& Clarke, V. (2006). Using thematic analysis in psychology. Qualitative Research in Psychology, 3(2), 77-101. https://doi.org/10.1191/1478088706qp063oa

Butler, K. (1997). The anatomy of resiliency. Psychotherapy Networker, 15, 22-33.

Camburn, E. M., \& Won Han, S. (2017). Teachers' professional learning experiences and their engagement in reflective practice: a replication study. School Effectiveness and School Improvement: an International Journal of Research, Policy and Practice, 28(2), 1-28. https://doi.org/10.1080/09243453.2017.1302968

CARRI. (2013). Definitions of Community Resilience: An Analysis A CARRI Report.

Cheng, E. C. K. (2017). Managing School-based Professional Development Activities. International Journal of Educational Management, 31(4), 445-454. https://doi.org/10.1108/IJEM-02-2016-0042.

Clarke, D., \& Hollingsworth, H. (2002). Elaborating a model of teacher professional growth. Teaching and Teacher Education 18, 947-967. https://doi.org/10.1016/S0742-051X(02)00053-7

Cloitre, M., Martin, N., \& Linares, O. (2005). Children's resilience in the face of trauma. New York: University Child Study Center.

Cohen, P. (1997). Rethinking the youth question: Education, labour and cultural studies. London: Macmillan Press. https://doi.org/10.1007/978-1-349-25390-6

Costa, A., \& Kallick, B. (1993). Through the lens of a critical friend. Educational Leadership, 51(2), 49-51.

Creswell, J. W. (2007). Qualitative Inquiry and Research Design: Choosing Among Five Approaches. Thousand Oaks, CA: Sage Publications.

Creswell, J. W. (2014). Research design: Qualitative, quantitative, and mixed methods approaches. Thousand Oaks, CA: Sage Publications.

Garet, M., Porter, S., Andrew, C., \& Desimone L. (2001). What makes professional development effective? Results from a national sample of teachers. American Educational Research Journal, 38(4), 915-945. https://doi.org/10.3102/00028312038004915

Garmezy, N., \& Rutter, M. (Eds.). (1983). Stress, coping, and development in children. New York, NY: McGraw-Hill.

Glesne, C. (2016). Becoming qualitative researchers: An introduction (5th ed.). Boston, MA: Pearson.

Gotovos, A. E. (2002). Education and Diversity (in Greek). Athens: Metaichmio.

Hall, S. (1992). New ethnicities. In J. Donald and A. Rattansi (Eds.), 'Race', culture, difference, 252-9. London: Sage.

Heckmann, J. J. (2008). The Case for Investing in Disadvantaged Young Children, 48-58. Retrieved 15/7/2016 from heckmanequation.org

Kossek, E. E., \& Burke, L. B. (2014). Developing Occupational and Family Resilience among US Migrant Farmworkers. Social Research: An International Quarterly, 81(2), 359-372. https://doi.org/10.1353/sor.2014.0022

Lee J., \& Pacini-Ketchabaw V. (2011). Immigrant girls as caregivers to younger siblings: a transnational feminist analysis. Gender and Education, 23(2), 105-119. https://doi.org/10.1080/09540251003674063

Lewis-Charp, H., \& Law, T. (2014). Student-centered learning: City Arts and Technology High School. Stanford, CA: Stanford Center for Opportunity Policy in Education. Retrieved 8/6/2015 from https:/edpolicy.stanford.edu/sites/default/files/SCOPE-student-centered-learning-CAT.pdf

Luckin, R., Clark, W., Avramides, K., Hunter, J., \& M. Oliver. (2017). Using teacher inquiry to support technology-enhanced formative assessment: a review of the literature to inform a new method. Interactive Learning Environments, 25(1), 85-97. https://doi.org/10.1080/10494820.2015.1121152 
Mahtani, M. (2001). 'I'm a blonde-haired, blue-eyed Black girl': Mapping mobile paradoxical spaces among multiethnic women in Toronto, Canada. In D. Parker and M. Song, (Eds.), Rethinking 'mixed race', 173-90. London: Pluto Press. https://doi.org/10.2307/j.ctt18fsbsq.12

Marshall, C., \& Rossman, G. B. (2011). Designing qualitative research (5th ed.). Thousand Oaks, CA: Sage Publications.

Masten, A. (2000). Children who overcome adversity to succeed in life. Minneapolis: MN: University of Minnesota Extension Service.

Ministry of Education and Culture (2010). New Curricula. Curriculum Development Unit, Ministry of Education and Culture Cyprus.

Ministry of Education and Culture (2015). Teachers' professional development and learning unified framework policy Report (March 2015). Retrieved from http://www.moec.gov.cy/archeia/2014_nees_protaseis_paideia/2015_03_23_protasi_epangelmatiki_mathisi_ek paideftikon.pdf, Retrieved 8/6/2015

Ministry of Education and Culture. (2016). Policy Paper on the Integration of students with migrant background in the Cyprus educational system. Retrieved 12/6/2017 from www.pi.ac.cy/pi/files/anakoinoseis/2016_2017/metanasteftiki_viografia.pdf

Modood, T. (1993). The number of ethnic minority students in British higher education: some grounds for optimism. Oxford Review of Education, 19(2), 167-182. https://doi.org/10.1080/0305498930190204

Modood, T. (2004). Capitals, ethnic identity and educational qualifications. Cultural trends, 13(2), 87-105. https://doi.org/10.1080/0954896042000267170

NASP. (2005). Resilience: Strategies for Parents and Educators Presented by: Western Elementary School Support Services -National Association of School Psychologists, (Adapted from: "Resiliency: Strategies for Parents and Educators," Helping Children at Home and School II: Handouts for Families and Educators, NASP, 2004).

NESSE. (2008). Education and Migration: Strategies for integrating migrant children in European schools and societies. A synthesis of research findings for policy-makers. An independent report submitted to the European Commission by the NESSE network of experts.

Nusche, D. (2009). What Works in Migrant Education? A Review of Evidence and Policy Options. OECD Education Working Paper No. 22.

O' Neil M., \& Hubbard P. (2010). Walking, sensing, belonging: ethno-mimesis as performative praxis. Visual Studies, 25(1), 46-58. https://doi.org/10.1080/14725861003606878

O’Neill, M. (2008). Transnational refugees: The transformative role of art? Forum: Qualitative Social Research] 9 (No 2): Article 59. Retrieved from http://nbnresolving.de/urn:nbn:de:0114- fqs0802590

O’Neill, M., Giddens, S., Breatnach, P., Bagley C., Bourne D., \& Judge T. (2002). Methodologies for social research: Ethno-mimesis as performative praxis. Sociological Review, 50(1), 69-88. https://doi.org/10.1111/1467-954X.00355

OECD. (2011). Against the Odds: Disadvantaged Students Who Succeed in School. OECD Publishing. https://doi.org/10.1787/9789264090873-en

OECD. (2012). Equity and Quality in Education: Supporting Disadvantaged Students and Schools. OECD Publishing. https://doi.org/10.1787/9789264130852-en

OECD. (2015). Education at a Glance 2015: OECD Indicators. OECD Publishing. https://doi.org/10.1787/eag-2015-en

OECD. (2016). OECD resilience systems analysis Turning strategy into action. Brief number 02. Retrieved 1/1/16 from http://www.oecd.org/dac/conflict-fragility-resilience/risk-resilience/

Ong, A. (1999). Flexible Citizenship: The Cultural Logics of Transnationality. Duke University Press.

Opfer, V. D., \& Pedder, D. (2011). Conceptualizing Teacher Professional Learning. Review of Educational Research, 81(3), 376-407. https://doi.org/10.3102/0034654311413609

Park, N., Peterson, C., \& Seligman, M. E. P. (2006). Character strengths in fifty-four nations and the fifty US states. The Journal of Positive Psychology, 1(3), 118-129. https://doi.org/10.1080/17439760600619567 
Parra-Cardona, J. R., Bulock, L. A., Imig, D. R., Villarruel, F. A., \& Gold, S. J. (2006). Trabajando Duro Todos Los Dvas: Learning from the Life Experiences of Mexican-Origin Migrant Families. Family Relations, 55(3), 361-375. https://doi.org/10.1111/j.1741-3729.2006.00409.x

Rattansi, A. (2005). Racism: Contemporary perspectives. London: Sage.

Ronnerman, K. (2003) Action research: educational tools and the improvement of practice. Educational Action Research, 11(1), 9-22. https://doi.org/10.1080/09650790300200206

Rotas, A. (2004). Is 'refugee art' possible? Third Text, 18(1), 51-60. https://doi.org/10.1080/0952882032000182767

SIRIUS. (2014). Sirius policy briefs series. Retrieved 8/6/2015 from http://www.sirius-migrationeducation.org/publications/

Swaffield, S., \& MacBeath, J. (2005). School self-evaluation and the role of a critical friend. Cambridge Journal of Education, 35(2), 239-252. https://doi.org/10.1080/03057640500147037

Tellis, W. M. (1997). Introduction to Case Study. The Qualitative Report, 3(2), 1-14. https://doi.org/10.1108/10650749710187617

The World Bank. (2014). Teacher Policies in the Republic of Cyprus.

Walsh, F. (2003). Family Resilience: A Framework for Clinical Practice. Family Process, 42(1), 1-18. https://doi.org/10.1111/j.1545-5300.2003.00001.x

Winnicott, D. W. (1982). Playing and reality. London: Routledge.

Wylie, J. (2005). A single day's walking: Narrating self and landscape on the South West Coast Path. Transactions of the Institute of British Geographers, 30(2), 234-47. https://doi.org/10.1111/j.1475-5661.2005.00163.x

Yin, R. K. (1994). Case study research: design and methods. Sage Publications.

\section{Notes}

Note 1. Data from PISA 2012 show that across OECD countries what is more strongly associated with performance than students' immigrant background is their socio-economic status. Actually PISA reveals that it is not the concentration of immigrant students in a school but, rather, the concentration of disadvantaged students in schools that hinders the achievement of both immigrants and non-immigrants (OECD, 2015). According to the PISA studies there are also differences in and between countries, concluding that right conditions being provided, the educational gap between migrant and native students can be limited (Nusche, 2009). In certain countries (e.g. Australia, Canada and New Zealand), there were no performance differences between migrant and native students. Similarly, across OECD countries migrant students from the same country of origin and similar socio-economic background often perform differently in different school systems. For example, in PISA 2012 Albanian students in Greece had scored 50 points higher in mathematics than Albanian students with similar socio-economic status in Montenegro. It is worth mentioning that this difference is very close to the average difference in performance between Greece and Montenegro (OECD, 2015).

Note 2. Health Education, a subject in the syllabuses of Primary and Secondary Education Schools (Ministry of Education and Culture, 2010), aims at protecting, improving and promoting the physical, mental and social well-being of pupils by strengthening their personality and by upgrading their social and natural environment. 